\title{
Factorial Analysis on Biovinegar Production from Pineapple Waste Using Mixed Strains
}

\author{
Y. Selvanathan ${ }^{1}$, S. M. Shaarani ${ }^{1}$, N. Masngut ${ }^{1}, 2^{*}$ \\ ${ }^{1}$ Faculty of Chemical and Process Engineering Technology, Universiti Malaysia Pahang, 26300 Pahang, Malaysia. \\ ${ }^{2}$ Centre of Excellence for Advanced Research in Fluid Flow (CARIFF), Universiti Malaysia Pahang, 26300 Pahang, Malaysia.
}

\begin{abstract}
One of the feasible approaches to oversee pineapple waste deposit without harming the environment is by converting these build-ups into value added items such as biovinegar. The objective of this work is to screen the fermentation parameter to identify the best condition and significant parameters affecting the fermentation. Five independent parameters were investigated, namely; temperature, fermentation time, addition of glucose, part and condition of waste. Fractional factorial design of Design Expert@ software was used to investigate the effect of independent parameters as well as the interaction between parameters on the biovinegar production. The work was carried out by natural fermentation in which naturally occurred microorganism readily available on the raw materials (pineapple waste) was used. The result showed that the order of parameter significance in acid production was as follows: temperature $>$ addition of glucose $>$ fermentation time > part of waste > condition of waste. The interaction parameter of fermentation time and addition of glucose had the strongest effect on the acid production. The best fermentation condition was carried out using pineapple peel juice at $30^{\circ} \mathrm{C}$ for 8 days in an anaerobic condition with 50 $\mathrm{g} / \mathrm{L}$ glucose addition. Under these conditions, acid production was $1.12 \% \mathrm{w} / \mathrm{v}$ in which acetic acid concentration was $0.94 \% \mathrm{w} / \mathrm{v}$. The product $\mathrm{pH}$ was recorded at 3.57 . The product yield and productivity were recorded at $0.1699 \mathrm{~g} / \mathrm{g}$ and $0.0489 \mathrm{~g} / \mathrm{L} . \mathrm{h}$, respectively. Exploration on producing biovinegar using mixed strains and pineapple waste as substrate could be another way to reduce environmental pollution and at the same time turning this waste into value added product. Moreover, using the natural fermentation together with the carry over benefit of the pineapple benefitted the quality of produced biovinegar.
\end{abstract}

\section{KEYWORDS}

Biovinegar, mixed strains, fractional factorial design, pineapple waste, natural fermentation.

\section{INTRODUCTION}

During pineapple processing, the stem, crown, core and peel were removed and discarded as waste. As much as $50 \%$ of the total fruit weight were discarded as waste during canning (Salim, 2016). It can be estimated that more than 150, $000 \mathrm{~kg}$ of pineapple waste was produced each year in Malaysia. This waste disposal can be problematic because it is high in moisture and sugar content and prone to microbial spoilage emitting foul gaseous such as $\mathrm{H}_{2}, \mathrm{CO}_{2}$ and $\mathrm{CH}_{4}$ ( $\mathrm{Lun}$ et al., 2014).

Usually, biovinegar production utilizes specific microorganism strain for the fermentation to occur. However, it has been reported that biovinegar from single strain fermentation is inferior to that from the mixed strains (Liu et al., 2019). The use of mixed strain together with the carry over benefit of the raw materials were seen to improve the aroma and quality of biovinegar (Liu et al., 2019). Study by Liu et al. (2019) and Chen et al. (2017) proved that mixed strains apple and citrus biovinegar were rich in flavour, aroma and antioxidant activity than its single strain. The natural occurring microorganism in the pineapple waste were identified from Monera and Fungi kingdom with various genus such as Pseudomonas, Erwinia, Xanthomonas, Acidovorax and Acetobacter for the bacteria species, meanwhile, Penicillium, Geotrichum, Fusarium, Botrytis, Collectotrichum, Muco, Monilinia, Rhizopus and Phtyophthora for fungi species (Bhat et al., 2014).

Previous study on pineapple biovinegar focused on one factor at a time (OFAT) investigation in which much time was needed to complete if a lot of parameters were considered (Raji et al., 2012). The data analysis also limited to only one parameter contribution instead of parameter interaction. No study has been reported on multiple parameters using statistical tool such as fractional factorial design on the biovinegar production.

Temperature is one of the important parameters to be investigated as it would affect greatly on the growth of microorganism thus directly affecting the acid production. Study by Ghosh et al. (2014), Chakraborty et al. (2017a) and Kong et al. (2018) reported a temperature range between 30 and $32{ }^{\circ} \mathrm{C}$ was optimum for the growth of Acetobacter and yeast. Meanwhile, Arroyo-López et al. (2009) found that a special thermotolerant Acetobacter was able to sustain its 
growth at elevated temperature of $40{ }^{\circ} \mathrm{C}$. Thus, for the screening study, the range of parameter should be wider than the reported one, hence the chosen temperature was between 30 and $50{ }^{\circ} \mathrm{C}$. Fermentation time is another important parameter that should be considered to ensure the alcohol and acid production at sufficient and appropriate track of time. Previous study stated that it took between 11 to 40 days for the alcoholic and acidic fermentation to complete (Raji et al., 2012; Roda et al., 2017). Carbon source is another important element for continued growth of microorganism. Raji et al. (2012) carried out a fermentation using pineapple peel with the addition of $25 \mathrm{~g} / \mathrm{L}$ glucose, thus it was decided to apply a wide range of glucose addition in this screening study which was between 0 and $50 \mathrm{~g} / \mathrm{L}$.

The objective of this work is to screen the fermentation parameter to identify the best condition and significant parameters affecting the fermentation. Factorial analysis was performed by using two level factorial of Design Expert ${ }^{\circledR}$ software. Two level factorial is a statistical method based on multivariate non - linear model that is useful in studying interactions of various parameters affecting the process (Bergquist, 2015; Saunders \& Eccleston, 1992). The fermentation kinetics including product yield and its productivity was also developed. These were determined using the best conditions suggested by the software.

\section{MATERIALS AND METHODS}

\section{Raw materials}

The pineapple fruits used for this study were from MD2 species and was provided generously by Pekan Pina Sdn. Bhd. The fruits were cleaned and cut to separate the peel and core. Cleaned peel and core were pureed to produce a slurry. The juice substrate was prepared by extracting the slurry through a filter with pore size of $20 \mu \mathrm{m}$. All substrate was kept at $-20{ }^{\circ} \mathrm{C}$ until further use.

\section{Experimental design}

In this work, five parameters which were fermentation time, temperature, addition of glucose, condition and part of waste were taken into account to investigate their effects on the percentage of acid production using $2^{5-1}$ fractional factorial design produced 16 runs of experiments. The design of experiment was performed by Design Expert巴 software where all parameters were randomized. Table 1 shows the design parameters and levels were coded as -1 (low level) and +1 (high level) where low and high levels indicates the lowest and the highest range of the parameters. Batch natural fermentation without agitation was carried out anaerobically using pineapple waste substrate with the readily available microorganism on the substrate itself. Each fermentation run was conducted in a $100 \mathrm{~mL}$ serum bottle with $50 \mathrm{~mL}$ working volume. Once fermentation ceased, sample was collected and centrifuged at $8000 \mathrm{rpm}$ for 15 minutes and subjected to analysis. Carried out analysis were $\mathrm{pH}$, acid content, acetic acid concentration and reducing sugar concentration. The response of the experimental design was analyzed using ANOVA based on the $p$-value with $95 \%$ of confidence level. Experimental data was analyzed to determine the percentage contribution of all parameters and interaction between them.

Table 1. Parameters and actual values of coded levels used in the $2^{5-1}$ fractional factorial design experiments.

\begin{tabular}{|c|c|c|c|c|c|c|}
\hline \multirow{2}{*}{ No. } & \multirow{2}{*}{ Parameters } & \multirow{2}{*}{ Coded } & \multirow{2}{*}{ Type of parameters } & \multicolumn{2}{|c|}{ Actual values of coded levels } & \multirow{2}{*}{ Units } \\
\hline & & & & -1 & +1 & \\
\hline 1 & Fermentation time & $\bar{A}$ & Numerical & 8 & 18 & Days \\
\hline 2 & Temperature & B & Numerical & 30 & 50 & ${ }^{\circ} \mathrm{C}$ \\
\hline 3 & Addition of glucose & C & Numerical & 0 & 50 & $g / L$ \\
\hline 4 & Condition of waste & D & Categorical & Juice & Slurry & _ \\
\hline 5 & Part of waste & $\mathrm{E}$ & Categorical & Core & Peel & - \\
\hline
\end{tabular}

\section{Analytical methods}

\section{pH and acid content}

A pH meter (Mettler-Toledo AG, B211773648, 8603 Schwerzenbach) was used for all pH value measurements which were carried out at the end of the fermentation. The total acidity was estimated using $1.0 \mathrm{~mL}$ biovinegar sample, phenolphthalein and a neutralizing agent of $0.1 \mathrm{M} \mathrm{NaOH}$, which yielded total acid content in percentage. This method was adopted from Raji et al. (2012).

\section{Acetic acid concentration}

The acetic acid concentration was quantified using HPLC (Agilent technologies, model number 7111B, serial number DEAET00386) adopted from Zhang et al. (2017) with modification. Samples were filtrated with a $0.45 \mu \mathrm{m}$ membrane filter. A Synergy Hydro C18 250 organic acids column $(300 \times 4.6 \mathrm{~mm}$, Japan $)$ with sulphuric acid as mobile phase at 0.5 $\mathrm{mL} / \mathrm{min}$ was used, measured with a UV detector at $221 \mathrm{~nm}(1260 \mathrm{VWD}, 1200$ series; Agilent Technologies).

\section{Reducing sugar concentration}

The reducing sugar was estimated using dinitrosalicylic acid (DNS) method of Teixeira et al. (2012). 1.5 mL of biovinegar sample with dilution of citrate buffer was added into $3 \mathrm{~mL}$ DNS reagent and the mixtures was heated at $100^{\circ} \mathrm{C}$ 
for $5 \mathrm{~min}$. After cooling to room temperatures, $2 \mathrm{~mL}$ of the mixture was withdrawn. Each sample was scanned with UV/VIS spectrophotometer (Model Genesys 50, serial number of 9A3WO53007) at wavelength $540 \mathrm{~nm}$ to obtain the optical density (OD) values and compared with the glucose calibration curve. Glucose calibration curve was developed earlier at concentration range between $0-100 \mathrm{~g} / \mathrm{L}$ using the same procedure as the sample.

\section{Fermentation kinetic development}

Product yield, $Y_{p / s}$ was calculated by dividing the product (concentration of acetic acid) over substrate (consumed reducing sugar concentration). The productivity was calculated by dividing acetic acid concentration with its respected fermentation time.

\section{EXPERIMENTAL RESULTS AND DISCUSSION}

\section{Screening on parameters affecting biovinegar production}

Screening of parameters affecting the biovinegar production was carried out using $2^{5-1}$ fractional design to determine the degree of the effect to the response. Table 2 shows total acids concentration obtained from natural fermentation was between 0.93 to $1.22 \% \mathrm{w} / \mathrm{v}$.

Table 2. The result of the $2^{6}$ fractional factorial experiments.

\begin{tabular}{|c|c|c|c|c|c|c|}
\hline \multirow{3}{*}{ Run } & \multicolumn{5}{|c|}{ Parameters } & \multirow{3}{*}{$\begin{array}{r}\text { Acid concentration } \\
(\% \mathrm{w} / \mathrm{v})\end{array}$} \\
\hline & A: Time & B: Temperature & $\begin{array}{l}\text { C: Addition of } \\
\text { glucose }\end{array}$ & $\begin{array}{l}\text { D: Condition of } \\
\text { waste }\end{array}$ & $\begin{array}{l}\text { E: Part of } \\
\text { waste }\end{array}$ & \\
\hline & Days & ${ }^{\circ} \mathrm{C}$ & $\%$ & - & - & \\
\hline 1 & 18 & 50.00 & 5.00 & Core & Slurry & 1.04 \\
\hline 2 & 18 & 50.00 & 0.00 & Peel & Slurry & 0.84 \\
\hline 3 & 18 & 30.00 & 5.00 & Peel & Slurry & 1.19 \\
\hline 4 & 18 & 50.00 & 0.00 & Core & Juice & 0.93 \\
\hline 5 & 8 & 50.00 & 5.00 & Core & Juice & 1.06 \\
\hline 6 & 8 & 30.00 & 5.00 & Peel & Juice & 1.17 \\
\hline 7 & 18 & 30.00 & 5.00 & Core & Juice & 1.13 \\
\hline 8 & 8 & 50.00 & 0.00 & Peel & Juice & 1.05 \\
\hline 9 & 8 & 30.00 & 5.00 & Core & Slurry & 1.08 \\
\hline 10 & 18 & 50.00 & 5.00 & Peel & Juice & 1.22 \\
\hline 11 & 8 & 30.00 & 0.00 & Core & Juice & 1.14 \\
\hline 12 & 8 & 50.00 & 5.00 & Peel & Slurry & 0.99 \\
\hline 13 & 18 & 30.00 & 0.00 & Core & Slurry & 1.04 \\
\hline 14 & 8 & 30.00 & 0.00 & Peel & Slurry & 1.32 \\
\hline 15 & 18 & 30.00 & 0.00 & Peel & Juice & 1.05 \\
\hline 16 & 8 & 50.00 & 0.00 & Core & Slurry & 1.04 \\
\hline
\end{tabular}

\section{Main effect and its interaction on biovinegar production}

The analysis of variance (ANOVA) was done to determine the statistical significance of the model suggested by the software. The significance of the model can be determined using $F$-values, while the $p$-values were used to examine the significance of each coefficient as shown in Table 3 . From the model, $F$-value was 24.95 indicated that only $1.13 \%$ chances that the model's $F$-value of this large could occur due to noise. Low $p$-value $(p<0.0001)$ showing the significance of the corresponding parameter (Masoumi et al., 2011). The model term effects $A, B, C, E, A C, A D, B C$ and $C D$ were statistically significant in affecting the acid production.

The satisfactory $R^{2}$ value of 0.9901 indicates best model fits the experimental values and predicted well. The final equations in term of coded parameters is shown in Equation (1):

$$
\begin{gathered}
Y=0.18-\left(9.844 \times 10^{-3}\right) A-\left(4.531 \times 10^{-3}\right) B+\left(4.719 \times 10^{-3}\right) C-\left(2.219 \times 10^{-3}\right) D-\left(3.906 \times 10^{-3}\right) E \\
+\left(2.301 \times 10^{-3}\right) A B+\left(4.406 \times 10^{-3}\right) A C-\left(5.031 \times 10^{-3}\right) A D+\left(3.281 \times 10^{-3}\right) A E+\left(9.969 \times 10^{-3}\right) B C- \\
\left(2.469 \times 10^{-3}\right) B D-\left(3.594 \times 10^{-3}\right) C D
\end{gathered}
$$

Where $Y$ is the response of acid yield, $A$ is temperature, $B$ is fermentation time, $C$ is addition of glucose, $D$ is condition of waste and $E$ is part of waste. Parameters of $A, B, C, D$ and $E$ are referred as the main effect, while $A B, A C, A D, A E$, $B C, B D$ and $C D$ are the interaction effects. From the equation, main parameters $A, B, D$ and $E$ were negatively affected the fermentation. Meanwhile, parameter $C$ affected the fermentation positively. Then, the interaction of parameters: $A B$, $A C, A E$ and $B C$ positively affected while $A D, B D$ and $C D$ negatively affected the acid production. Positive effect means, as the parameter increased, the acid production also increased, while the negative effect was vice versa. 
Table 3. Test of significance for regression coefficient.

\begin{tabular}{llllll}
\hline Source & Sum of squares & df & Mean of squares & F-value & $p$-value \\
\hline Model & $5.406 \times 10-3$ & 12 & $4.505 \times 10^{-4}$ & 24.95 & 0.0113 \\
A-Temperature & $1.550 \times 10-3$ & 1 & $1.550 \times 10^{-3}$ & 85.86 & 0.0027 \\
B-Fermentation time & $3.25 \times 10^{-4}$ & 1 & $3.285 \times 10^{-4}$ & 18.19 & 0.0236 \\
C-Addition of glucose & $3.563 \times 10^{-4}$ & 1 & $3.563 \times 10^{-4}$ & 19.73 & 0.0212 \\
D-Condition of waste & $7.877 \times 10^{-5}$ & 1 & $7.877 \times 10^{-5}$ & 4.36 & 0.1280 \\
E-Part of waste & $2.441 \times 10^{-4}$ & 1 & $2.441 \times 10^{-4}$ & 13.52 & 0.0348 \\
AC & $3.106 \times 10^{-4}$ & 1 & $3.106 \times 10^{-4}$ & 17.20 & 0.0255 \\
AD & $4.050 \times 10^{-4}$ & 1 & $4.050 \times 10^{-4}$ & 22.43 & 0.0178 \\
BC & $1.590 \times 10^{-3}$ & 1 & $1.590 \times 10^{-3}$ & 88.05 & 0.0026 \\
CD & $2.066 \times 10^{-4}$ & 1 & $2.066 \times 10^{-4}$ & 11.44 & 0.0430 \\
Residual & $1.806 \times 10^{-5}$ & 3 & $1.806 \times 10^{-5}$ & & \\
\hline
\end{tabular}

Table 4 shows the contribution of main parameter and its interaction to acid production. The highest contributor was parameter $A$ with $28.39 \%$ contribution. Previous study showed an optimum temperature range for growth of Acetobacter and yeast which commonly used in biovinegar production was between 30 and $32{ }^{\circ} \mathrm{C}$ (Chakraborty et al., 2017b; Ghosh et al., 2014; Kong et al., 2018). Meanwhile, special thermo-tolerant Acetobacter was able to grow up to $40^{\circ} \mathrm{C}$ (ArroyoLópez et al., 2009). Thus, optimum temperature in biovinegar production will depend on the microorganism present either in the raw material or added as a starter. Wider temperature range was usually tested in factorial screening analysis. Thus, in this study, the temperature range was investigated between 30 and $50{ }^{\circ} \mathrm{C}$.

The second highest contributing parameter was parameter C, with $6.52 \%$. A study by Raji et al. (2012) reported that the optimum level of glucose concentration was $2.5 \%$ which is lower than the current study. Another parameter that was also considered significant was parameter B with the percentage of contribution of $6.02 \%$. Liu et al. (2019) took five days for alcoholic fermentation then additional five days for acetous fermentation to produce apple vinegar of $0.9 \%$ acid content using mixed strains.

Table 4. Percentage of contribution of main parameter and their interaction.

\begin{tabular}{lr}
\hline Parameter & Contribution (\%) \\
\hline A-Temperature & 28.39 \\
B-Fermentation time & 6.02 \\
C-Addition of glucose & 6.52 \\
D-Condition of waste & 1.44 \\
E-Part of waste & 4.47 \\
AC & 5.69 \\
BC & 29.12 \\
\hline
\end{tabular}

\section{Effect of main parameters}

The effects of two independent parameters on the acid production are shown in Figure 1. Acid production decreased with increased temperature from 30 to $50{ }^{\circ} \mathrm{C}$, as shown in Figure 1a. Although an optimum temperature range for Acetobacter and yeast was between 30 and $32^{\circ} \mathrm{C}$, but for special thermotolerant microorganism, it was able to grow at temperature up to $40^{\circ} \mathrm{C}$ (Arroyo-López et al., 2009; Chakraborty et al., 2017b; Ghosh et al., 2014; Kong et al., 2018). Taking this into account, the temperature had to be kept in a wider range for screening study which was between 30 and $50{ }^{\circ} \mathrm{C}$. Acid production was evidently increased as higher initial glucose concentration exist in the substrate as shown in Figure 1 b. Glucose was used by the microorganism as the carbon source for both biosynthesis and energy production to support the microorganism growth and product formation.

Figure $1 \mathrm{c}$ showed that acid production was slightly decreased over fermentation time from $8^{\text {th }}$ day to $18^{\text {th }}$ day. Similar result was reported by Kong et al. (2018) where acetic acid content was increased at the beginning of fermentation and eventually decreased by $2.34 \%$ as the fermentation continued until $12^{\text {th }}$ day. Acetic acid evaporates easily, thus influencing the loss of acetic acid through evaporation when exposed to air, which might be the reason in acid decreased over time (Sanarico et al., 2003). Figure 1d showed that acid production was slightly decreased by $0.01 \% \mathrm{w} / \mathrm{v}$ when the substrate was changed from peel waste to core waste. It can be concluded that there was no significant difference of acid production from both parts of waste. Study by Kodagoda and Marapana (2017) stated that pineapple peel contains higher lignocellulose than the core. Lignocellulose mainly composed of three groups of polymers, namely celulose, hemicellulose and lignin. Cellulose and hemicellulose are sugar rich fractions of interest for use in fermentation process, since microorganisms may use the sugars for growth (Mussatto \& Teixeira, 2010). Therefore, maybe core do not have enough sugar to support the microorganism growth and acid production. Whereas, the peel has additional carbon sources from the lignocellulosic related to results shown in Figure 1d. This would be aiding in acid production that matches with the result of this study where higher acid was produced from the peel than the core substrate. 


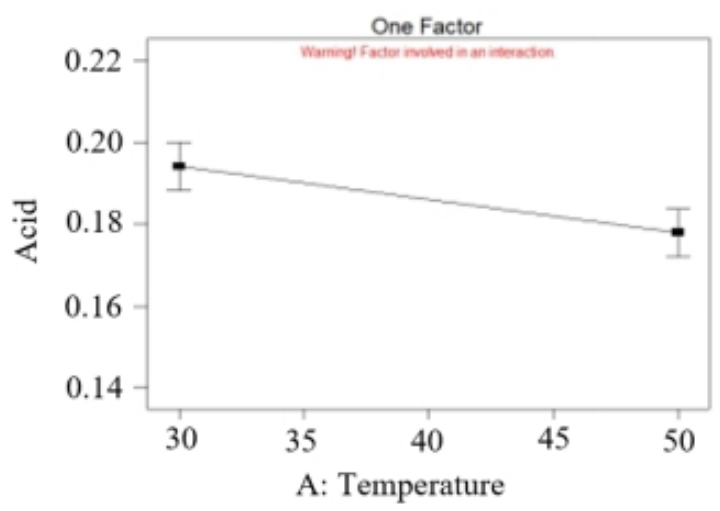

(a)

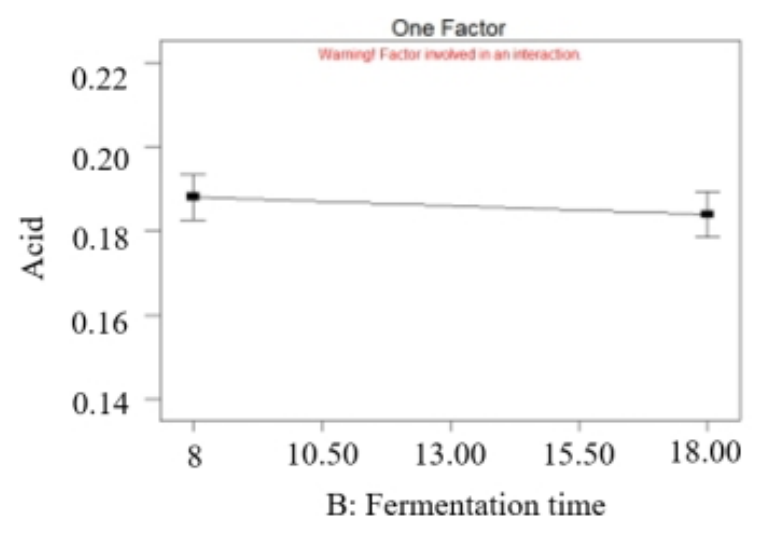

(c)

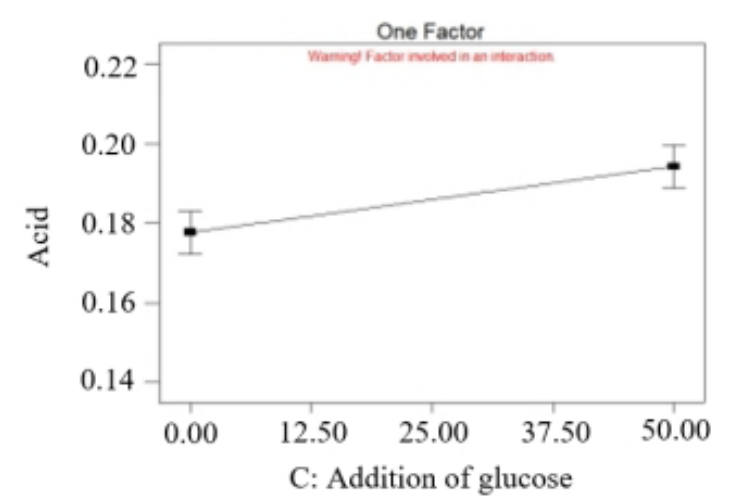

(b)

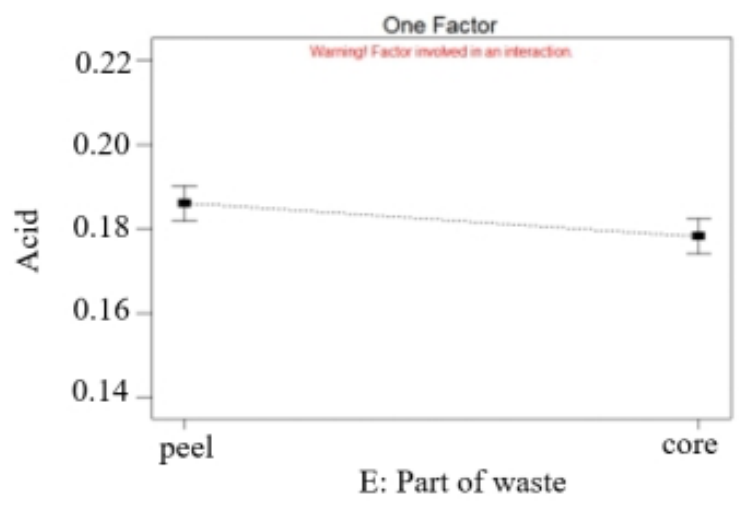

(d)

Figure 1. Effect of main parameters to acid production. (a) temperature; (b) addition of glucose; (c) fermentation time; (d) part of waste

\section{Effect of parameter interaction}

Figure 2 shows selected parameter interaction which has significant contribution towards acid production. At low temperature $\left(30^{\circ} \mathrm{C}\right)$ in both substrates (with and without glucose addition) higher acid was produced than at high temperature $\left(50^{\circ} \mathrm{C}\right.$ ) as shown in Figure $2 \mathrm{a}$. Substrate with $50 \mathrm{~g} / \mathrm{L}$ glucose addition produced a maximum of $0.2 \% \mathrm{w} / \mathrm{v}$ final acidity in which it was $0.025 \% \mathrm{w} / \mathrm{v}$ higher than that without glucose addition. It is apparent that fermentation maintained at an optimum temperature will thrive as reported by Sossou et al. (2009) and Roda et al. (2017). Temperature has to be kept in a wider range for screening study which between 30 and $50{ }^{\circ} \mathrm{C}$ considering the variety of mixed strain might exist in the substrate (Arroyo-López et al., 2009; Chakraborty et al., 2017b; Ghosh et al., 2014; Kong et al., 2018).

At short fermentation time (eight days) in both substrates (with and without glucose addition) produced acid at 0.19 $\% \mathrm{w} / \mathrm{v}$ as shown in Figure 2b. But when fermentation time increased to 18 days, substrate with additional glucose content produced higher acid production by $0.035 \% \mathrm{w} / \mathrm{v}$ than that without glucose addition. Enough carbon source throughout the fermentation was important to sustain microorganism growth and product formation at extended time (Vijayakumar et al., 2015). 


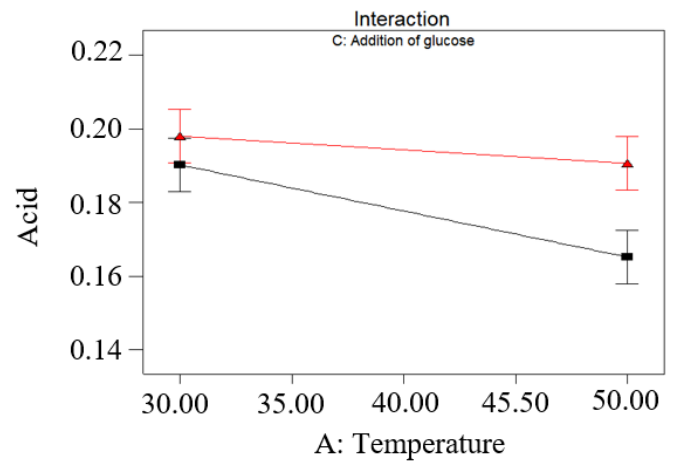

(a)

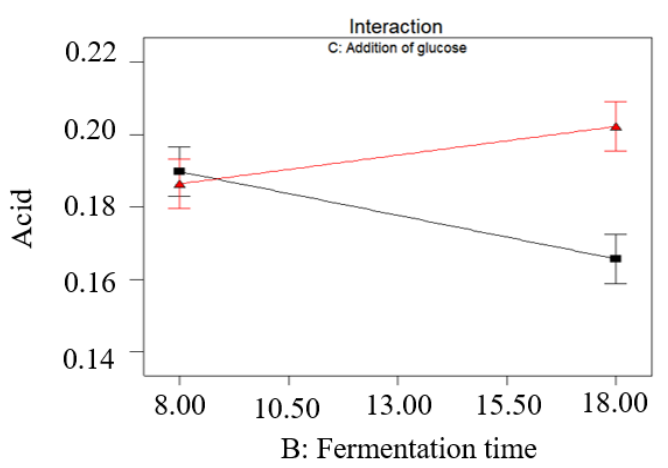

(b)

Figure 2. Effects of parameters interaction on acid production. (a) temperature and addition of glucose; (b) fermentation time and addition of glucose. Red line: $50 \mathrm{~g} / \mathrm{L}$ glucose addition; black line: no glucose addition.

\section{Validation of model}

The model suggested by DoE® was validated experimentally through triplicate runs. The best fit condition suggested by the software was carried out at $30^{\circ} \mathrm{C}$, with $50 \mathrm{~g} / \mathrm{L}$ glucose addition, for eight days of natural fermentation, using juice from the peel. The desirability of these condition was 0.867 . The acid production was recorded at $1.12 \% \mathrm{w} / \mathrm{v}$ with error of $2.91 \%$ than the predicted production. The error was below $30 \%$, thus it is an acceptable error for biological experiment (Sharif et al., 2017). The fermentation kinetic developed in biovinegar production is shown in Table 5.

Table 5. Fermentation kinetics of biovinegar production.

\begin{tabular}{lr}
\hline Parameter & Value \\
\hline Fermentation time (days) & 8 \\
Concentration of acid (\% w/v) & 1.12 \\
Predicted concentration of acid $(\%$ w/v) & 1.15 \\
Concentration of acetic acid $(\%$ w/v) & 0.94 \\
Initial reducing sugar available (\% w/v) & 5.81 \\
Final reducing sugar available $(\%$ w/v) & 0.28 \\
Reducing sugar consumption (\%) & 95.04 \\
Initial pH & 4.00 \\
Final pH & 3.57 \\
Yield of acetic acid, $\mathbf{Y}_{p / s}(\mathbf{g} / \mathbf{g})$ & 0.1699 \\
Productivity of acetic acid (g/L.h) & 0.0489 \\
Validation error (\%) & 2.91 \\
\hline
\end{tabular}

\section{CONCLUSION}

Factorial screening of biovinegar utilizing pineapple waste by natural fermentation was successfully conducted. Fractional factorial screening was able to determine the effect of the five parameters on acid production. Fermentation temperature contributed the most to the production of acid as much as $28.39 \%$. This was followed by the addition of glucose, fermentation time and part of waste with contribution of $6.52 \%, 6.02 \%$ and $4.47 \%$, respectively. Based on the ANOVA, the model was statistically significant with $R^{2}$ of 0.9901 . Two main parameter interactions were identified to be significant; between temperature (A) and addition of glucose (C), also fermentation time (B) and addition of glucose (C). Validation run proved that the model and suggested condition by the software was reliable, producing biovinegar with $1.12 \% \mathrm{w} / \mathrm{v}$ acidity with an error of $2.91 \%$. The results show that fractional factorial design is suitable to be used in the investigation of many parameters with a minimum number of experiments.

\section{ACKNOWLEDGMENT}

This work was financially supported by the Fundamental Research Grant Scheme (FRGS) from the Ministry of Higher Education, Malaysia through FRGS/1/2018/TK02/UMP/02/10 and UMP-Pekan Pina industrial grant of UIC190802. 


\section{REFERENCES}

Arroyo-López, F. N., Orlić, S., Querol, A., \& Barrio, E. (2009). Effects of temperature, pH and sugar concentration on the growth parameters of Saccharomyces cerevisiae, S. kudriavzevii and their interspecific hybrid. International Journal of Food Microbiology, 131, 120-127

Bergquist, B. (2015). Analysis of an unreplicated 22 factorial experiment performed in a continuous process. Total Quality Management \& Business Excellence, 26(10), 1083-1094

Bhat, S. V., Akhtar, R., \& Amin, T. (2014). An Overview on the Biological Production of Vinegar. International Journal of Fermented Foods, 3(2), 139-155

Chakraborty, K., Saha, S. K., Raychaudhuri, U., \& Chakraborty, R. (2017a). Vinegar production from vegetable waste: Optimization of physical condition and kinetic modeling of fermentation process. Indian Journal of Chemical Technology, 24, 508-516

Chakraborty, K., Saha, S. K., Raychaudhuri, U., \& Chakraborty, R. (2017b). Vinegar from Bael (Aegle marmelos): A Mixed Culture Approach. Indian Chemical Engineer, 60(4), 384-395

Chen, Y., Huang, Y., Bai, Y., Fu, C., Zhou, M., Gao, B., Wang, C., Li, D., Hu, Y., \& Xu, N. (2017). Effects of mixed cultures of Saccharomyces cerevisiae and Lactobacillus plantarum in alcoholic fermentation on the physicochemical and sensory properties of citrus vinegar. LWT-Food Science and Technology, 84, 753-763

Ghosh, S., Chakraborty, R., Chatterjee, A., \& Raychaudhuri, U. (2014). Optimization of media components for the production of palm vinegar using response surface methodology. Institute of Brewing \& Distilling, 120, 550-558

Kodagoda, G., \& Marapana, U. (2017). Analysis of proximate composition and physicochemical properties of pineapple wastes. Sri Lanka Association for the Advancement of Science, 94

Kong, C. T., Ho, C. W., Ling, J. W. A., Lazim, A., Fazry, S., \& Lim, S. J. (2018). Chemical Changes and Optimisation of Acetous Fermentation Time and Mother of Vinegar Concentration in the Production of Vinegar-like Fermented Papaya Beverage. Sains Malaysiana, 47(9), 2017-2026

Liu, Q., Li, X., Sun, C., Wang, Q., Yao, H., Yang, W., Zheng, Z., Jiang, S., \& Wu, X. (2019). Effects of mixed cultures of Candida tropicalis and aromatizing yeast in alcoholic fermentation on the quality of apple vinegar. 3 Biotech, 9, 1-10

Lun, O. K., Wai, T. B., \& Ling, L. S. (2014). Pineapple cannery waste as a potential substrate for microbial biotranformation to produce vanillic acid and vanillin. International Food Research Journal, 21(3), 953-958

Masoumi, H. R. F., Kassim, A., Basri, M., \& Abdullah, D. K. (2011). Determining Optimum Conditions for Lipase-Catalyzed Synthesis of Triethanolamine (TEA)-Based Esterquat Cationic Surfactant by a Taguchi Robust Design Method. Molecules, 16(6), 46724680

Mussatto, S. I., \& Teixeira, J. A. (2010). Lignocellulose as raw material in fermentation processes. In A. Méndez-Vilas (Ed.), Current Research, Technology and Education Topics in Applied Microbiology and Microbial Biotechnology (Vol. 2, pp. 719-1620). Spain: FORMATEX Research Centre

Raji, Y. O., Jibril, M., Misau, I. M., \& Danjuma, B. Y. (2012). Production of Vinegar from Pineapple Peel International Journal of Advanced Scientific Research and Technology, 3(2), 656-666

Roda, A., Lucini, L., Torchio, F., Dordoni, R., Faveri, D. M. D., \& Lambri, M. (2017). Metabolite profiling and volatiles of pineapple wine and vinegar obtained from pineapple waste. Food Chemistry, 229, 734-742

Salim, S. (2016). Transforming The Malaysian Pineapple Industry. 5th International Plantation Industry Conference \& Exhibition (IPiCEx2016), 24

Sanarico, D., Motta, S., Bertolini, L., \& Antonelli, A. (2003). HPLC Determination of Organic Acids in Traditional Balsamic Vinegar of Reggio Emilia. Journal of Liquid Chromatography \& Related Technologies, 26(13), 2177-2187

Saunders, I. W., \& Eccleston, J. A. (1992). Experimental Design For Continuous Processes. Austral. J. Statist., 34(1), 77-89

Sharif, N. S. A. M., Thor, E. S., Zainol, N., \& Jamaluddin, M. F. (2017). Optimization of Ferulic Acid Production from Banana Stem Waste Using Central Composite Design. Environmental Progress \& Sustainable Energy, 36(4), 1217-1223

Sossou, S. K., Ameyapoh, Y., Karou, S. D., \& Souza, C. d. (2009). Study of Pineapple Peelings Processing into Vinegar by Biotechnology. Pakistan Journal of Biological Sciences, 12(11), 859-865

Teixeira, R. S. S., Silva, A. S. A. d., Ferreira-Leitão, V. S., \& Bon, E. P. d. S. (2012). Amino acids interference on the quantification of reducing sugars by the 3,5-dinitrosalicylic acid assay mislead carbohydrase activity measurements. Carbohydrate Research, $363,33-37$

Vijayakumar, R., Al-Aboody, M. S., \& Sandle, T. (2015). A review of melanized (black) fungal contamination in pharmaceutical products - incidence, drug recall and control measures. Journal of Applied Microbiology, 120(4), 831-841

Zhang, L., Huanga, J., Zhoua, R., \& Wua, C. (2017). Evaluating the feasibility of fermentation starter inoculated with Bacillus amyloliquefaciens for improving acetoin and tetramethylpyrazine in Baoning bran vinegar. International Journal of Food Microbiology, 255, 42-50 